Article

\title{
Iminium Salts by Meerwein Alkylation of Ehrlich’s Aldehyde
}

\author{
Carmen Froschauer ${ }^{1,2}$, Hedda K. Weber ${ }^{2}$, Volker Kahlenberg ${ }^{3}$, Gerhard Laus ${ }^{1, *}$ \\ and Herwig Schottenberger ${ }^{1, *}$
}

1 Faculty of Chemistry and Pharmacy, University of Innsbruck, 6020 Innsbruck, Austria; E-Mail: carmen.froschauer@uibk.ac.at

2 Competence Centre of Wood Composites and Wood Chemistry K-Plus, Altenbergerstraße 69, 4021 Linz, Austria; E-Mail: h.weber@kplus-wood.at

3 Institute of Mineralogy and Petrography, University of Innsbruck, 6020 Innsbruck, Austria; E-Mail: volker.kahlenberg@uibk.ac.at

* Authors to whom correspondence should be addressed; E-Mails: gerhard.laus@uibk.ac.at (G.L.); herwig.schottenberger@uibk.ac.at (H.S.); Tel.: +43-512-507-57004 (H.S.);

Fax: +43-512-507-57099 (G.L.;H.S.).

Received: 25 January 2013; in revised form: 6 March 2013 / Accepted: 11 March 2013 /

Published: 18 March 2013

\begin{abstract}
Dimethylamino)benzaldehyde is alkylated at the $\mathrm{N}$ atom by dialkyl sulfates, $\mathrm{MeI}$, or $\mathrm{Me}_{3} \mathrm{O} \mathrm{BF}_{4}$. In contrast, ethylation by $\mathrm{Et}_{3} \mathrm{O} \mathrm{BF}_{4}$ occurs selectively at the $\mathrm{O}$ atom yielding a quinoid iminium ion. 4-(Diethylamino)benzaldehyde is alkylated only at $\mathrm{O}$ by either Et or Me oxonium reagent. The iminium salts are prone to hydrolysis giving the corresponding hydrotetrafluoroborates. Five crystal structures were determined.
\end{abstract}

Keywords: alkylation; Ehrlich's aldehyde; iminium salt; quinoid; quinone

\section{Introduction}

During unrelated work, the need arose for low-melting quaternary ammonium salts ("ionic liquids") bearing an aldehyde functional group. Our obvious choice was 4-(dimethylamino)benzaldehyde (Ehrlich's aldehyde) as inexpensive starting material which was to be $N$-alkylated. Common alkylating reagents such as dialkyl sulfates or methyl iodide readily gave the desired products $[1,2]$. However, a surprising selectivity was observed when trialkyloxonium tetrafluoroborates (Meerwein reagents) were employed. Thus, methylation occurred at the $\mathrm{N}$ atom as expected, whereas ethylation took place at the 
$\mathrm{O}$ atom. The crystal structures of the new compounds and byproducts were determined by single crystal X-ray diffraction (Table 1).

\section{Results and Discussion}

As noted above, for most of the different methods of alkylating 4-(dialkylamino)benzaldehydes (Figure 1a), including the use of trimethyloxonium tetrafluoroborate, the electrophilic attack occurs at the aniline $\mathrm{N}$ atom as expected, whereas Meerwein ethylation takes place at the carbonyl $\mathrm{O}$ atom, creating the quinoid iminium ion $\mathbf{1}$ in high yield and purity. Only traces of $\mathrm{N}$-alkyl derivative of 4-(diethylamino)benzaldehyde were observed with either Et or Me oxonium reagent. Iminium ions are very reactive electrophilic intermediates, allowing a large range of nucleophiles to be trapped. For example, cyclizations involving iminium ions belong to the most powerful methods of forming nitrogen-containing heterocycles [3]. They are easily available by various well-established methods, but unprecedented pathways towards new iminium vehicles are emerging by serendipity, thus inviting multifaceted follow-up chemistry [4]. Iminium species are sensitive compounds and are typically prepared immediately prior to use. In the present case, the new iminium salts can be stored under an inert atmosphere for prolonged periods at room temperature. They are however prone to hydrolysis in solution, yielding the corresponding protic salts $\mathbf{2}$ and 5, which gave suitable single crystals. Exhibiting the interesting motif of a quinoid spacer between an imine moiety and an enol ether, the new bright green iminium salts 1 and 4 (Figure 1b) belong to the subfamily of quinone imine dyes, featuring specific reactivity patterns on their own [5]. Analogous products of O-alkylation and silylation were obtained from the related 4,4'-bis(dimethylamino)benzophenone [6,7]. Another example was found in 3,6-bis(dimethylamino)-9-ethoxyacridine [8]. The N-alkylated product, 4-(trimethylammonio)benzaldehyde, is known as a useful precursor for 4-fluorobenzaldehyde [9,10]. The product of $\mathrm{N}$-alkylation was converted to the low-melting triflimide 3 by ion metathesis, thus achieving the goal of the initial unrelated project. Protonation of Ehrlich's aldehyde has also been reported to result in low-melting salts [11], and two crystal structures of such salts are known [12,13].

Figure 1. (a) Alkylation of 4-(dialkylamino)benzaldehydes with Meerwein reagents; (b) Colorful reaction of Ehrlich's aldehyde resulting in green crystals of iminium salt $\mathbf{1}$.

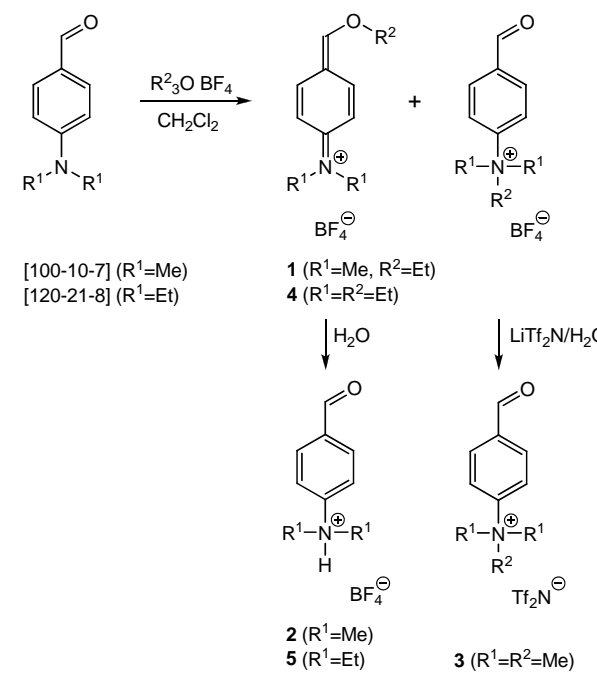

(a)

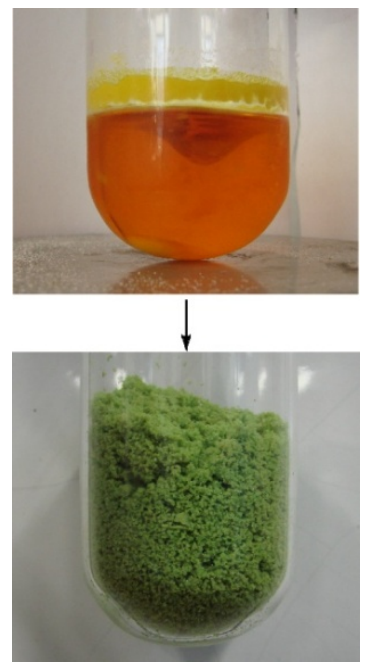

(b) 
Table 1. Crystal data and structure refinement details.

\begin{tabular}{|c|c|c|c|c|c|}
\hline Compound & 1 & 2 & 3 & 4 & 5 \\
\hline Chemical formula & $\mathrm{C}_{11} \mathrm{H}_{16} \mathrm{NO} \cdot \mathrm{BF}_{4}$ & $\mathrm{C}_{9} \mathrm{H}_{12} \mathrm{NO} \cdot \mathrm{BF}_{4}$ & $\mathrm{C}_{10} \mathrm{H}_{14} \mathrm{NO} \cdot \mathrm{C}_{2} \mathrm{~F}_{6} \mathrm{NO}_{4} \mathrm{~S}_{2}$ & $\mathrm{C}_{13} \mathrm{H}_{20} \mathrm{NO} \cdot \mathrm{BF}_{4}$ & $\mathrm{C}_{11} \mathrm{H}_{16} \mathrm{NO} \cdot \mathrm{BF}_{4}$ \\
\hline$M_{\mathrm{r}}$ & 265.06 & 237.01 & 444.37 & 293.11 & 265.06 \\
\hline Crystal system & Monoclinic & Monoclinic & Triclinic & Triclinic & Triclinic \\
\hline Space group & $C 2 / c$ & $P 2_{1} / n$ & $P \overline{1}$ & $P \overline{1}$ & $P \overline{1}$ \\
\hline$a / \AA$ & $18.9425(5)$ & $8.4727(4)$ & $7.7374(4)$ & $8.1170(12)$ & $7.2055(5)$ \\
\hline$b / \AA$ & $7.4564(3)$ & $13.5659(6)$ & $10.3506(7)$ & $9.2368(16)$ & $9.0529(6)$ \\
\hline$c / \AA$ & $21.134(1)$ & $10.4411(5)$ & $12.6004(8)$ & $10.6937(17)$ & $10.2060(7)$ \\
\hline$\alpha /^{\circ}$ & 90 & 90 & $72.577(6)$ & $67.069(15)$ & $94.378(6)$ \\
\hline$\beta /^{\circ}$ & $118.979(7)$ & $109.730(6)$ & $73.231(5)$ & $77.760(13)$ & $90.403(6)$ \\
\hline$\gamma /{ }^{\circ}$ & 90 & 90 & $72.301(9)$ & $89.080(13)$ & $97.839(5)$ \\
\hline$V / \AA^{3}$ & $2611.3(2)$ & $1129.64(9)$ & $895.34(10)$ & $719.6(2)$ & $657.50(8)$ \\
\hline$Z$ & 8 & 4 & 2 & 2 & 2 \\
\hline$D_{\mathrm{x}} / \mathrm{g} \cdot \mathrm{cm}^{-3}$ & 1.35 & 1.39 & 1.65 & 1.35 & 1.34 \\
\hline$\mu / \mathrm{mm}^{-1}$ & 1.08 & 0.13 & 0.39 & 1.03 & 0.12 \\
\hline Crystal size $/ \mathrm{mm}^{3}$ & $0.32 \times 0.24 \times 0.24$ & $0.32 \times 0.32 \times 0.02$ & $0.28 \times 0.16 \times 0.12$ & $0.20 \times 0.20 \times 0.12$ & $0.32 \times 0.2 \times 0.08$ \\
\hline$F(000) / \mathrm{e}$ & 1104 & 488 & 452 & 308 & 276 \\
\hline \multirow[t]{2}{*}{$\Theta$ range $/^{\circ}$} & $4.8-67.6$ & $2.6-25.2$ & $2.8-25.4$ & $4.6-67.5$ & $3.2-25.3$ \\
\hline & $-22 \leq \mathrm{h} \leq 16$ & $-10 \leq \mathrm{h} \leq 10$ & $-7 \leq \mathrm{h} \leq 9$ & $-9 \leq \mathrm{h} \leq 9$ & $-8 \leq \mathrm{h} \leq 7$ \\
\hline \multirow[t]{2}{*}{$h, k, l$ range } & $-8 \leq \mathrm{k} \leq 8$ & $-16 \leq \mathrm{k} \leq 16$ & $-11 \leq \mathrm{k} \leq 12$ & $-11 \leq \mathrm{k} \leq 10$ & $-10 \leq \mathrm{k} \leq 10$ \\
\hline & $-19 \leq 1 \leq 25$ & $-11 \leq 1 \leq 12$ & $-14 \leq 1 \leq 15$ & $-10 \leq 1 \leq 12$ & $-12 \leq 1 \leq 9$ \\
\hline Measured reflections & 7103 & 10599 & 5493 & 4283 & 4097 \\
\hline Independent reflections $\left(R_{\text {int }}\right)$ & $2337(0.022)$ & $2020(0.033)$ & $3248(0.019)$ & $2421(0.027)$ & $2369(0.025)$ \\
\hline Observed reflections $[I \geq 2 \sigma(I)]$ & 1902 & 1641 & 2529 & 1928 & 1893 \\
\hline Restraints/parameters & $21 / 185$ & $0 / 153$ & $0 / 251$ & $0 / 188$ & $132 / 261$ \\
\hline$R_{1} / w R_{2}[I \geq 2 \sigma(I)]$ & $0.059 / 0.172$ & $0.039 / 0.11$ & $0.029 / 0.067$ & $0.043 / 0.108$ & $0.039 / 0.084$ \\
\hline$R_{1} / w R_{2}$ (all data) & $0.069 / 0.181$ & $0.048 / 0.116$ & $0.039 / 0.071$ & $0.055 / 0.119$ & $0.053 / 0.093$ \\
\hline$\Delta \rho_{\max / \min } / \mathrm{e} \AA^{-3}$ & $0.50 /-0.33$ & $0.32 /-0.28$ & $0.35 /-0.34$ & $0.18 /-0.20$ & $0.17 /-0.17$ \\
\hline
\end{tabular}


The quinoid nature of the ring can be readily recognized by the presence of two short double bonds, $1.343(4) \AA$ and 1.350(4) $\AA$, and four long single bonds, from 1.418(4) $\AA$ to $1.436(5) \AA$. The two exocyclic bonds, $\mathrm{C}=\mathrm{N}$ with $1.330(3) \AA$ and $\mathrm{C}=\mathrm{C}$ with $1.375(4) \AA$, are clearly double bonds. The molecular structure of the ion pair and the packing in the unit cell $(Z=8)$ are shown in Figure 2.

Figure 2. (a) Ion pair (ellipsoids at 50 percent probability level); (b) Packing of compound 1 in the unit cell.

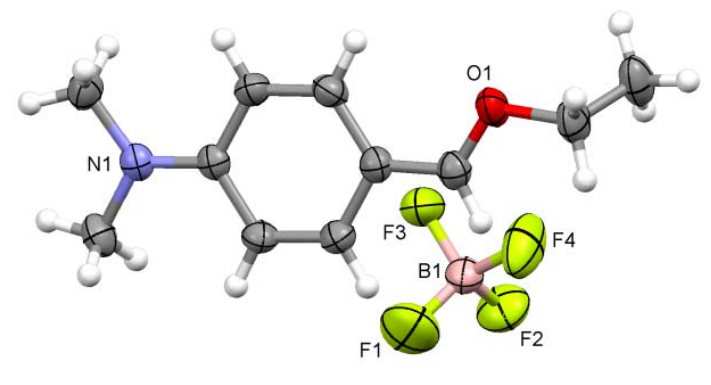

(a)

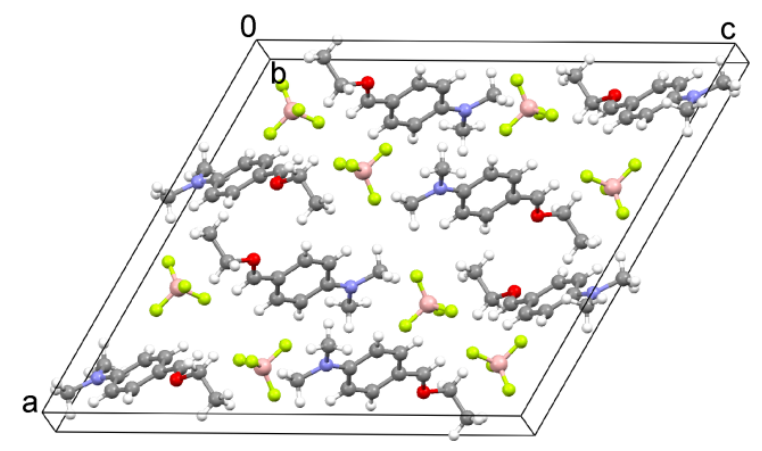

(b)

\subsection{4-(Dimethylamino)benzaldehyde hydrotetrafluoroborate (2)}

This protic salt was obtained by hydrolysis of the quinone 1. An interionic hydrogen bond is

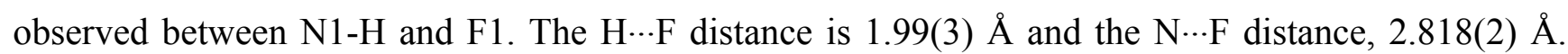
The $\mathrm{N} \cdots \mathrm{H} \cdots \mathrm{F}$ angle was found to be $152(2)^{\circ}$. The bond lengths in the ring, ranging from $1.378(2) \AA$ to 1.391(3) $\AA$, reveal its aromatic character. The two exocyclic bonds, C-N with 1.478(2) $\AA$ and C-C with 1.473(3) $\AA$, are typical single bonds. The molecular structure of the ion pair and the packing in the unit cell $(Z=4)$ are shown in Figure 3.

Figure 3. (a) Ion pair (ellipsoids at 50 percent probability level); (b) Packing of compound 2 in the unit cell.

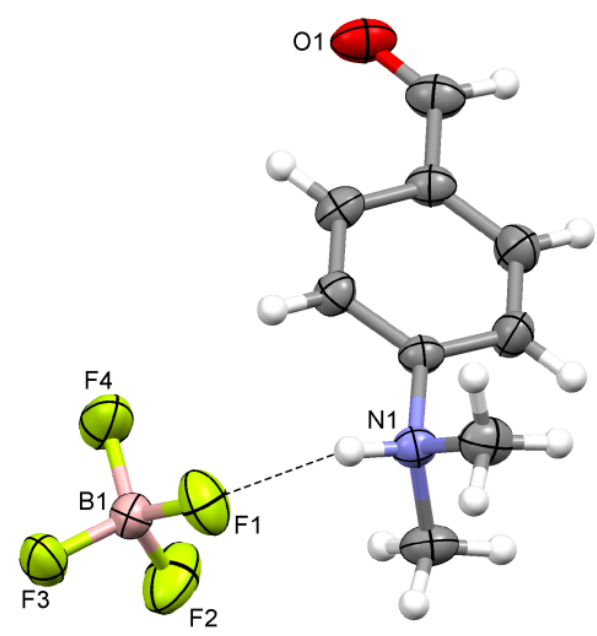

(a)

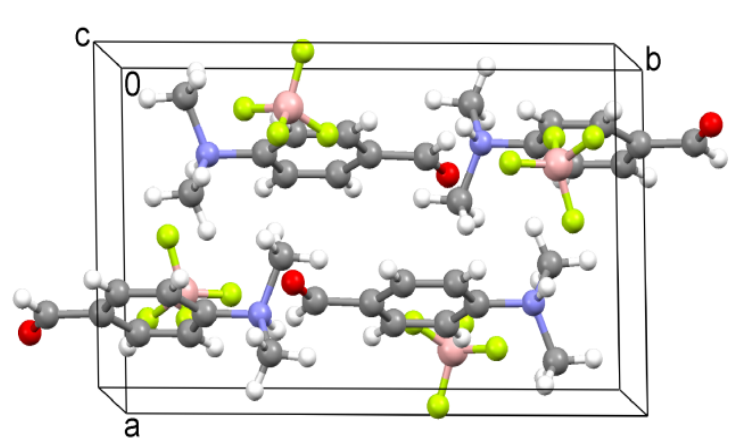

(b) 


\subsection{4-(Trimethylammonio)benzaldehyde bis(trifluoromethylsulfonyl)imide (3)}

The 4-(trimethylammonio)benzaldehyde cation obtained by methylation of Ehrlich's aldehyde using $\mathrm{Me}_{3} \mathrm{O} \mathrm{BF}_{4}$ was converted by ion metathesis and isolated as triflimide, a low-melting salt. Again, the bond lengths in the ring, ranging from 1.379(3) $\AA$ to $1.386(2) \AA$, indicate an aromatic system. The exocyclic single bonds, C-N with 1.500(2) $\AA$ and C-C with 1.482(3) $\AA$, are longer than in the protic salt 2. The triflimide anion adopts a typical anti conformation [14] with a C-S1 $\cdots$ S2-C torsion angle of 167.1(1) ${ }^{\circ}$ and exhibits only weak $\mathrm{C}-\mathrm{H} \cdots \mathrm{O}$ interactions with the cation. The molecular structure of the ion pair and the packing in the unit cell $(Z=2)$ are shown in Figure 4.

Figure 4. (a) Ion pair (ellipsoids at 50 percent level); (b) Packing of compound 3.

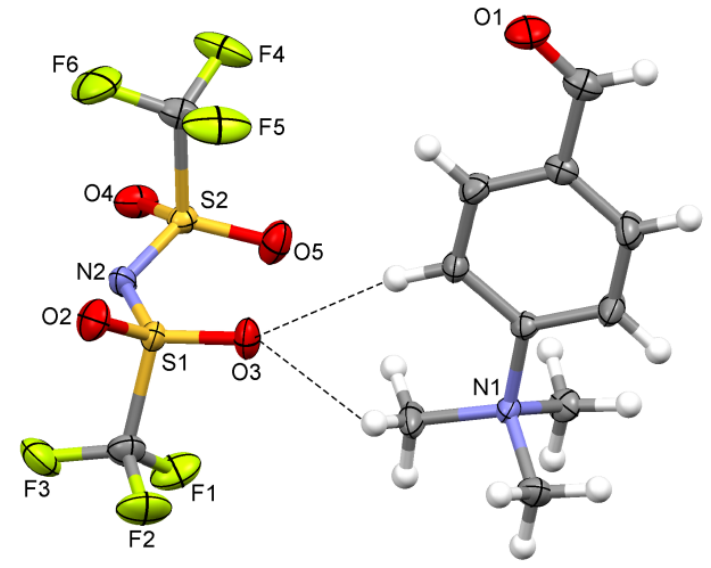

(a)

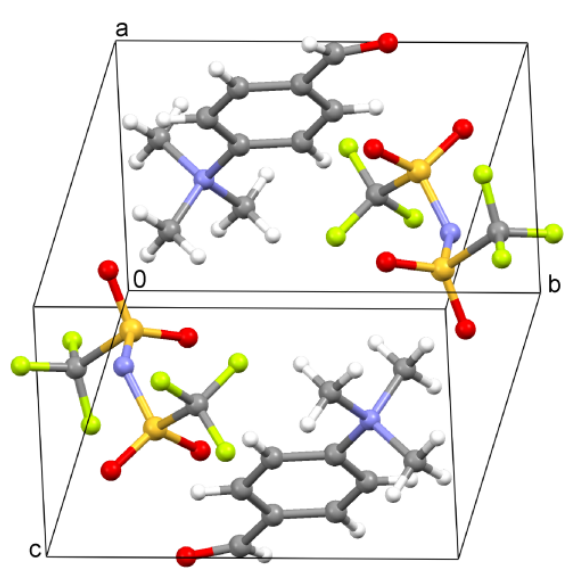

(b)

\subsection{N-(4-(Ethoxymethylene)cyclohexa-2,5-dienylidene)-N,N-diethylammonium Tetrafluoroborate (4)}

Again, the quinoid character of the ring can be seen by the presence of two short double bonds, $1.356(2) \AA$ and 1.359(2) $\AA$, and four long single bonds, from 1.420(3) $\AA$ to 1.439(2) $\AA$. The two exocyclic bonds, $\mathrm{C}=\mathrm{N}$ with $1.336(2) \AA$ and $\mathrm{C}=\mathrm{C}$ with $1.379(2) \AA$, are clearly double bonds. The molecular structure of the ion pair and the packing in the unit cell $(Z=2)$ are shown in Figure 5.

Figure 5. (a) Ion pair (ellipsoids at 50 percent level); (b) Packing of compound 4.

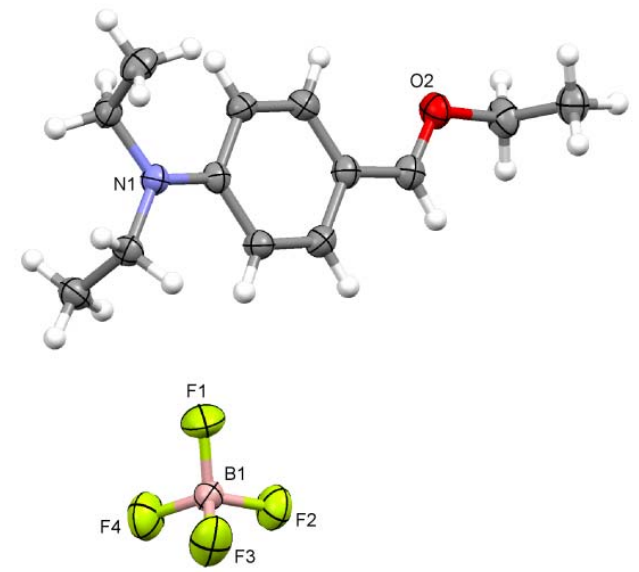

(a)

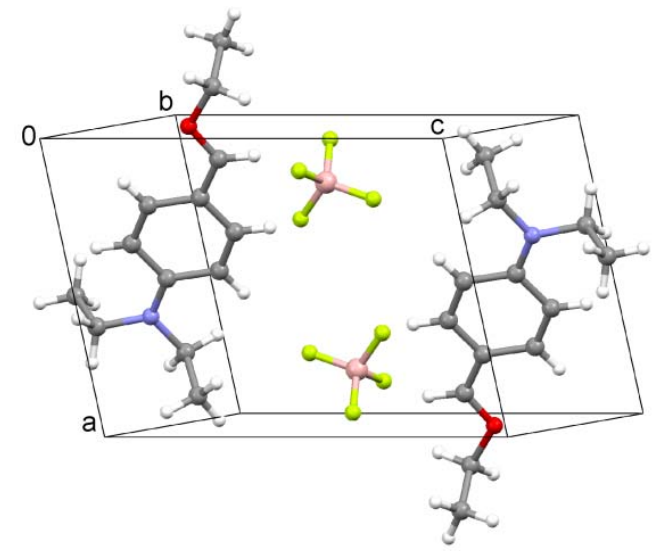

(b) 


\subsection{4-(Diethylamino)benzaldehyde Hydrotetrafluoroborate (5)}

The hydrolysis of quinone $\mathbf{4}$ gave this protic salt, in analogy to the conversion of $\mathbf{1}$ to $\mathbf{2}$. The anion exhibits positional disorder (ratio of components 0.33:0.26:0.41). A short hydrogen bond, as in compound 2, is observed between N1-H and F3. The bond lengths in the ring, from 1.376(2) $\AA$ to $1.388(2) \AA$, indicate aromatic character. The two exocyclic bonds, C-N with 1.476(2) $\AA$ and C-C with 1.474(2) $\AA$, are of almost equal length as in salt 2 . The molecular structure of the ion pair and the packing in the unit cell $(Z=2)$ are shown in Figure 6.

Figure 6. (a) Ion pair (ellipsoids at 50 percent probability level); (b) Packing of compound 5 in the unit cell.

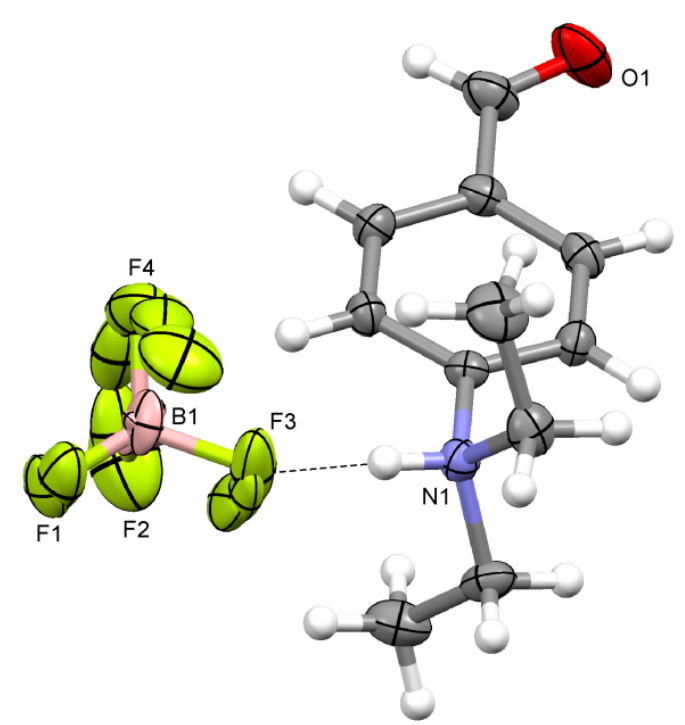

(a)

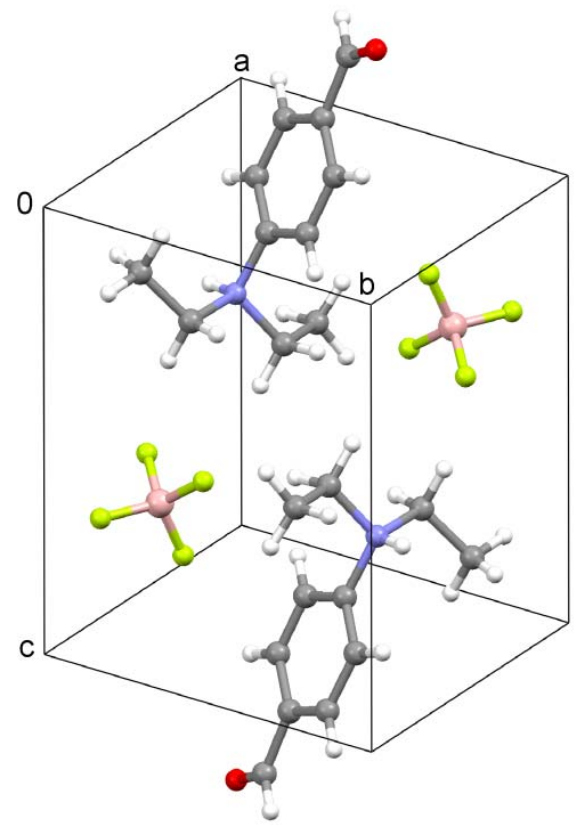

(b)

\section{Experimental Section}

Intensity data were collected on an Oxford Diffraction Gemini-R Ultra diffractometer with graphite-monochromatized $\mathrm{Cu} K \alpha(\mathbf{1}$ and $\mathbf{4})$ or $\mathrm{Mo} K \alpha(\mathbf{2}, \mathbf{3}$, and 5) radiation. Data were measured via $\omega$ scans, and an empirical absorption correction (multi-scan) was applied. CCDC reference numbers: 921104-921108. These data can be obtained free of charge from The Cambridge Crystallographic Data Centre.

3.1. N-(4-(Ethoxymethylene)cyclohexa-2,5-dienylidene)-N,N-dimethylammonium Tetrafluoroborate (1) and 4-(Dimethylamino)benzaldehyde Hydrotetrafluoroborate (2)

4-(Dimethylamino)benzaldehyde $(5.94 \mathrm{~g}, 39.8 \mathrm{mmol})$ was added to a solution of $\mathrm{Et}_{3} \mathrm{O} \mathrm{BF}_{4}(7.57 \mathrm{~g}$, $39.8 \mathrm{mmol})$ in anhydrous $\mathrm{CH}_{2} \mathrm{Cl}_{2}(10 \mathrm{~mL})$ in an argon atmosphere. The colour of the solution changed from yellow to red to brown and finally to green after 3 hours of stirring at room temperature. After $3.5 \mathrm{~h}$ anhydrous $\mathrm{Et}_{2} \mathrm{O}(50 \mathrm{~mL})$ was added, and a green solid precipitated. The solid was washed with 
anhydrous $\mathrm{Et}_{2} \mathrm{O}$ and dried. Single crystals of $\mathbf{1}$ and $\mathbf{2}$ were grown concomitantly by diffusion of hexane into a $\mathrm{CH}_{2} \mathrm{Cl}_{2}$ solution under inert gas.

1: ${ }^{1} \mathrm{H}$ NMR (300 MHz, DMSO-d $\left.)_{6}\right): 1.46(\mathrm{t}, 3 \mathrm{H}), 3.38(\mathrm{~s}, 6 \mathrm{H}), 4.73$ (q, 2H), $7.11(\mathrm{~d}, J=9.5 \mathrm{~Hz}, 2 \mathrm{H})$, $7.87(\mathrm{~d}, J=9.5 \mathrm{~Hz}, 2 \mathrm{H}), 8.68(\mathrm{~s}, 1 \mathrm{H}) \mathrm{ppm} ;{ }^{13} \mathrm{C} \mathrm{NMR}\left(75 \mathrm{MHz}, \mathrm{DMSO}-\mathrm{d}_{6}\right): 14.9,41.3(2 \mathrm{C}), 76.5$, 115.2 (2C), 128.0, 138.0, 159.7, $180.5 \mathrm{ppm}$.

2: ${ }^{1} \mathrm{H}$ NMR (300 MHz, DMSO-d 6 ): $3.04(\mathrm{~s}, 6 \mathrm{H}), 6.79(\mathrm{~d}, J=8.9 \mathrm{~Hz}, 2 \mathrm{H}), 7.68(\mathrm{~d}, J=8.9 \mathrm{~Hz}, 2 \mathrm{H})$, 9.66 (s, 1H) ppm; ${ }^{13} \mathrm{C}$ NMR (75 MHz, DMSO-d $)$ : 39.7 (2C), 111.1 (2C), 124.6, 131.6 (2C), 154.2, $189.9 \mathrm{ppm}$.

\subsection{4-(Trimethylammonio)benzaldehyde Bis(trifluoromethylsulfonyl)imide (3)}

4-(Dimethylamino)benzaldehyde (1.53 g, $10.3 \mathrm{mmol})$ was added to a solution of $\mathrm{Me}_{3} \mathrm{O} \mathrm{BF}_{4}(1.52 \mathrm{~g}$, $10.3 \mathrm{mmol})$ in anhydrous $\mathrm{CH}_{2} \mathrm{Cl}_{2}(50 \mathrm{~mL})$ under inert gas. The colour of the solution changed from yellow to orange to yellow-light green. After stirring at room temperature for $20 \mathrm{~h}$ anhydrous $\mathrm{Et}_{2} \mathrm{O}(50 \mathrm{~mL})$ was added, and a light orange solid formed, which was vacuum-dried. Then $\mathrm{K}_{2} \mathrm{CO}_{3}$ (1.42 g, $10.3 \mathrm{mmol}$ ), lithium bis(trifluoromethylsulfonyl)imide (1.71 g, $5.96 \mathrm{mmol}$ ), and $\mathrm{H}_{2} \mathrm{O}(50 \mathrm{~mL})$ were added and stirred at room temperature for $1 \mathrm{~h}$. The formation of a heavy organic phase was observed. The aqueous phase was discarded, and the lower phase was washed twice with $\mathrm{Et}_{2} \mathrm{O}$. After addition of $\mathrm{CH}_{2} \mathrm{Cl}_{2}(50 \mathrm{~mL})$ the organic phase was washed twice with water. The solvent was removed, and the resulting light-green product was vacuum-dried. Single crystals were obtained by diffusion of hexane into a solution in anhydrous $\mathrm{CH}_{2} \mathrm{Cl}_{2}$. m.p. $67-69^{\circ} \mathrm{C}$.

${ }^{1} \mathrm{H}$ NMR (300 MHz, DMSO-d 6 ): $3.65(\mathrm{~s}, 9 \mathrm{H}), 8.14-8.23(\mathrm{~m}, 4 \mathrm{H}), 10.11(\mathrm{~s}, 1 \mathrm{H}) \mathrm{ppm} ;{ }^{13} \mathrm{C}$ NMR (75 MHz, DMSO-d ${ }_{6}$ ): 56.4 (3C), 119.5 (q, $J=322 \mathrm{~Hz}$ ), 121.8 (2C), 130.9 (2C), 136.8, 151.1, 192.2 ppm.

\subsection{N-(4-(Ethoxymethylene) cyclohexa-2,5-dienylidene)-N,N-diethylammonium Tetrafluoroborate (4)}

4-(Diethylamino)benzaldehyde $(5.25 \mathrm{~g}, 29.6 \mathrm{mmol})$ was added to a solution of $\mathrm{Et}_{3} \mathrm{O} \mathrm{BF}_{4}(5.62 \mathrm{~g}$, $29.6 \mathrm{mmol})$ in anhydrous $\mathrm{CH}_{2} \mathrm{Cl}_{2}(15 \mathrm{~mL})$ under argon. The color of the solution changed from yellow to orange to yellow-green after $24 \mathrm{~h}$ of stirring at room temperature. Anhydrous $\mathrm{Et}_{2} \mathrm{O}(10 \mathrm{~mL})$ was added to precipitate a light green solid, which was filtered and dried. Single crystals were grown by diffusion of hexane into a solution in anhydrous $\mathrm{CH}_{2} \mathrm{Cl}_{2}$.

${ }^{1} \mathrm{H}$ NMR (300 MHz, DMSO-d $)_{6}$ : 1.23 (t, 6H), 1.46 (t, 3H), 3.74 (q, 4H), 4.73 (q, 2H), 7.13 (d, $J=9.2 \mathrm{~Hz}, 2 \mathrm{H}), 7.87(\mathrm{~d}, J=9.2 \mathrm{~Hz}, 2 \mathrm{H}), 8.69(\mathrm{~s}, 1 \mathrm{H}) \mathrm{ppm} ;{ }^{13} \mathrm{C}$ NMR $\left(75 \mathrm{MHz}, \mathrm{DMSO}-\mathrm{d}_{6}\right)$ : $12.6(2 \mathrm{C}), 15.0,46.2(2 \mathrm{C}), 76.5,115.0(2 \mathrm{C}), 128.4,138.4,158.3,180.3 \mathrm{ppm}$.

\subsection{4-(Diethylamino)benzaldehyde Hydrotetrafluoroborate (5)}

4-(Diethylamino)benzaldehyde (1.80 g, $10.2 \mathrm{mmol})$ was added to a solution of $\mathrm{Me}_{3} \mathrm{O} \mathrm{BF}_{4}(1.50 \mathrm{~g}$, $10.2 \mathrm{mmol})$ in anhydrous $\mathrm{CH}_{2} \mathrm{Cl}_{2}(30 \mathrm{~mL})$ under inert gas. The orange suspension turned into a green solution after stirring at room temperature for $24 \mathrm{~h}$. Addition of anhydrous $\mathrm{Et}_{2} \mathrm{O}(10 \mathrm{~mL})$ precipitated a light green solid. Unfortunately, only the hydrolyzed product crystallized by diffusion of hexane into a solution in $\mathrm{CH}_{2} \mathrm{Cl}_{2}$. 
${ }^{1} \mathrm{H}$ NMR (300 MHz, DMSO-d $): 1.11(\mathrm{t}, J=7.0 \mathrm{~Hz}, 6 \mathrm{H}), 3.43$ (q, $\left.J=7.0 \mathrm{~Hz}, 4 \mathrm{H}\right), 6.79$ (d, $J=8.9 \mathrm{~Hz}, 2 \mathrm{H}), 7.67(\mathrm{~d}, J=8.9 \mathrm{~Hz}, 2 \mathrm{H}), 9.64(\mathrm{~s}, 1 \mathrm{H}) \mathrm{ppm} ;{ }^{13} \mathrm{C}$ NMR $\left(75 \mathrm{MHz}, \mathrm{DMSO}-\mathrm{d}_{6}\right)$ : 12.3 (2C), 44.5 (2C), 111.3 (2C), 124.7, 132.0 (2C), 151.6, 189.7 ppm.

\section{Conclusions}

Of course, it would be far beyond the scope of this study, and even a chemist's lifespan could be consumed, to supplement this preliminary report by a representative selection of subsequent conversions. Consequently, this communication is focused mainly on crystallography. However, due to the affordability and ease with which these carbon-substituted representatives are accessible, it is also intended to stimulate further exploration of such iminium derivatives.

\section{Acknowledgments}

Financial support was provided by the Austrian government as well as by the Lenzing AG.

\section{References}

1. Fahim, H.A.; Galaby, M. Quaternary ammonium salts. The formation and decomposition of ethyldimethylanilinium salts. The synthesis of N-ethyl-N-methylanilines. J. Chem. Soc. 1950, 1950, 3529-3532.

2. Yuan, H.; Zhou, Z.; Xiao, J.; Liang, L.; Dai, L. Preparation of quarternary ammonium salt-tagged ferrocenylphosphine-imine ligands and their application to palladium-catalyzed asymmetric allylic substitution. Tetrahedron Asymmetry 2010, 21, 1874-1884.

3. Royer, J.; Bonin, M.; Micouin, L. Chiral heterocycles by iminium ion cyclization. Chem. Rev. 2004, 104, 2311-2352.

4. El Kaim, L.; Grimaud, L. Beyond the Ugi reaction: Less conventional interactions between isocyanides and iminium species. Tetrahedron 2009, 65, 2153-2171.

5. Brown, E.R. Quinonediimines, monoimines, and related compounds. In Chemistry of Quinonoid Compounds; Patai, S., Rappoport, Z., Eds.; Wiley: Chichester, UK, 1988; pp. 1231-1292.

6. Meerwein, H.; Florian, W.; Schön, N.; Stopp, G. Acid amide acetals, urea acetals, and lactam acetals (in German). Ann. Chem. 1961, 641, 1-39.

7. Emde, H.; Götz, A.; Hofmann, K.; Simchen, G. Reaktionen der Trialkylsilyl-trifluormethansulfonate, I. Synthese von Trialkylsilyl-Enolethern (in German). Ann. Chem. 1981, 1981, 1643-1657.

8. Elslager, E.F.; Haley, N.F.; McLean, J.R.; Perricone, S.C.; Potoczak, D.; Veloso, H.; Worth, D.F.; Wheelock, R.H. Inhibitors of platelet aggregation. 2. 9-\{[(Dialkylamino)alkyl]thio]-3(dimethylamino)acridines and related acridine derivatives. J. Med. Chem. 1971, 14, 782-788.

9. Bruus-Jensen, K.; Poethko, T.; Schottelius, M.; Hauser, A.; Schwaiger, M.; Wester, H.-J. Chemoselective hydrazone formation between HYNIC-functionalized peptides and ${ }^{18}$ F-fluorinated aldehydes. Nucl. Med. Biol. 2006, 33, 173-183.

10. Poethko, T.; Schottelius, M.; Thumshirn, G.; Hersel, U.; Herz, M.; Henriksen, G.; Kessler, H.; Schwaiger, M.; Wester, H.-J. Two-step methodology for high-yield routine radiohalogenation of peptides: ${ }^{18}$ F-labeled RGD and octreotide analogs. J. Nucl. Med. 2004, 45, 892-902. 
11. Shamsuri, A.A.; Abdullah, D.K. Protonation and complexation approaches for production of protic eutectic ionic liquids. J. Phys. Sci. 2010, 21, 15-28.

12. Dattagupta, J.K.; Saha, N.N. The crystal structure of p-dimethylaminobenzaldehyde hydrobromide. Acta Crystallogr. 1973, B29, 1228-1233.

13. Thakuria, H.; Borah, B.M.; Pramanik, A.; Das, G. Solid state synthesis and hierarchical supramolecular self-assembly of organic salt cocrystals. J. Chem. Cryst. 2007, 37, 807-816.

14. Laus, G.; Hummel, M.; Többens, D.M.; Gelbrich, T.; Kahlenberg, V.; Wurst, K.; Griesser, U.J.; Schottenberger, H. The 1:1 and 1:2 salts of 1,4-diazabicyclo[2.2.2]octane and bis(trifluoromethylsulfonyl)amine: Thermal behaviour and polymorphism. CrystEngComm 2011, 13, 5439-5446.

(C) 2013 by the authors; licensee MDPI, Basel, Switzerland. This article is an open access article distributed under the terms and conditions of the Creative Commons Attribution license (http://creativecommons.org/licenses/by/3.0/). 